\title{
Comprehensive Analysis of Chicken Vessels as Microvascular Anastomosis Training Model
}

\author{
Bo Young Kang*, Byung-Joon Jeon*, Kyeong-Tae Lee, Goo-Hyun Mun \\ Department of Plastic Surgery, Samsung Medical Center, Sungkyunkwan University School of Medicine, Seoul, Korea
}

Background Nonliving chickens are commonly used as a microvascular anastomosis training model. However, previous studies have investigated only a few types of vessel, and no study has compared the characteristics of the various vessels. The present study evaluated the anatomic characteristics of various chicken vessels as a training model.

Methods Eight vessels-the brachial artery, basilic vein, radial artery, ulnar artery, ischiatic artery and vein, cranial tibial artery, and common dorsal metatarsal artery-were evaluated in 26 fresh chickens and 30 chicken feet for external diameter (ED) and thicknesses of the tunica adventitia and media. The dissection time from skin incision to application of vessel clamps was also measured.

Results The EDs of the vessels varied. The ischiatic vein had the largest ED of $2.69 \pm 0.33 \mathrm{~mm}$, followed by the basilic vein $(1.88 \pm 0.36 \mathrm{~mm})$, ischiatic artery $(1.68 \pm 0.24 \mathrm{~mm})$, common dorsal metatarsal artery $(1.23 \pm 0.23 \mathrm{~mm})$, cranial tibial artery $(1.18 \pm 0.19 \mathrm{~mm})$, brachial artery $(1.08 \pm 0.15 \mathrm{~mm})$, ulnar artery $(0.82 \pm 0.13 \mathrm{~mm})$, and radial artery $(0.56 \pm 0.12 \mathrm{~mm})$, and the order of size was consistent across all subjects. Thicknesses of the tunica adventitia and media were also diverse, ranging from $74.09 \pm 19.91 \mu \mathrm{m}$ to $158.66 \pm 40.25 \mu \mathrm{m}$ (adventitia) and from $31.2 \pm 7.13 \mu \mathrm{m}$ to $154.15 \pm 46.48 \mu \mathrm{m}$ (media), respectively. Mean dissection time was $<3$ minutes for all vessels.

Conclusions Our results suggest that nonliving chickens can provide various vessels with different anatomic characteristics, which can allow trainees the choice of an appropriate microvascular anastomosis training model depending on their purpose and skillfulness.

Keywords Chickens / Models, educational / Anastomosis, surgical

\author{
Correspondence: Goo-Hyun Mun \\ Department of Plastic Surgery, \\ Samsung Medical Center, \\ Sungkyunkwan University School of \\ Medicine, 81 Ilwon-ro, Gangnam-gu, \\ Seoul 06351, Korea \\ Tel: $+82-2-3410-2233$ \\ Fax: +82-2-3410-0036 \\ E-mail: supramicro@gmail.com
}

*Bo Young Kang and Byung-Joon Jeon are first co-authors, equally contributing to this work.

No potential conflict of interest relevant to this article was reported.

Received: 17 May 2016 • Revised: 25 Sep $2016 \bullet$ Accepted: 4 Oct 2016

pISSN: 2234-6163 • elSSN: 2234-6171 • https://doi.org/10.5999/aps.2017.44.1.12 • Arch Plast Surg 2017;44:12-18

\section{INTRODUCTION}

Microanastomosis is an essential technique during reconstructive surgery. Accordingly, the need to improve skills before the actual operation has led to the development of various training models, including synthetic material and vessels in nonliving and living animals. Among them, vessels of living animals, such as rats, have been favored as a standard training model due to their distinct advantages, including real hemodynamic responses. However, training with living models requires animal purchase and disposal, and animal research ethics approval and authorized facilities are needed [1]. Furthermore, rat vessels weigh 200-300 g and are often too small for use by novices, considering their limited experience and skill. Thus, many surgeons have used nonliving animal models, such as fresh chickens, turkeys [2], and pig legs [3]. 
Chickens are preferred to other non-living animal models due to their low purchase price, easy storage, less preparation time, convenient disposal, and absence of ethics issues [4,5]. Various chicken vessels, such as the brachial artery [6], radial artery [4], ischiatic vessel, popliteal artery, tibial artery [7], and dorsal artery of the foot [8] have been used. However, most studies have evaluated the characteristics of only one or two chicken vessels, and few studies have comprehensively analyzed various types of vessel, which might provide valuable information for identifying the nature of each vessel and choosing appropriate training models. The present study compared the characteristics of various chicken vessels that have been used as microvascular anastomosis training models and presents dissection methods for each vessel.

\section{METHODS}

Twenty-six fresh chickens (weight, 650-1,420 g) and 30 frozen chicken feet (Cobb strain) were used. Eight vessels - the brachial artery, basilic vein, ulnar artery, radial artery in the upper extremity and ischiatic artery, ischiatic vein, cranial tibial artery, and common dorsal metatarsal artery in the lower extremitywere analyzed.

We measured the external diameter (ED), the thicknesses of the adventitia and media of each vessel and their dissection time. The ED was measured using a surgical microscope $(\mathrm{Cal}$ Zeiss Inc., Jena, Germany) at $25 \times$ magnification. A micro-ruler with 0.05-mm intervals (Micro Scale, Crownjun Kono, Tokyo, Japan) and stainless steel gauge with 0.05-mm intervals (model 58698; Shinwa Measuring Tools Inc., Niigata, Japan) were used for measurements. The EDs of the vessels, except the ischiatic artery and vein, were measured at their midpoint. The EDs of the ischiatic artery and vein were measured at the upper onethird level of the femur, as the upper two-thirds of the ischiatic vessel with a length of 5-6 cm is easily exposed, while the distal one-third, with more branches, lies deeper. We selected 9 fresh chickens, of relatively consistent weight, and 12 frozen feet and harvested 5-mm-long vessels for the measurement of vessel wall thickness together with the perivascular tissue, to prevent injury. Tissues were fixed in $10 \%$ neutral buffered formalin, embedded in paraffin, and sectioned at $4-\mu \mathrm{m}$ thickness. The tissues were stained with hematoxylin and eosin to distinguish the structure of the tunica adventitia and tunica media. We measured the thicknesses of the adventitia and media using the NIS Elements AR software (Nikon, Tokyo, Japan) under a light microscope at $400 \times$ magnification (Fig. 1). Dissection time was defined as the time from skin incision and isolating the vessel with the naked eye to applying vessel clamps under a microscope. A single senior resident who had 1 month of microanastomosis training experience measured the dissection time.

\section{Dissection technique}

The upper extremities were divided into the upper wing (human humerus) and the lower wing (human forearm). The lower extremities consisted of the thigh and lower leg or drumstick (Fig. 2). The 2 wings and 2 legs were separated from the trunk using a blade by carefully cutting the tendons and joint capsules, so as not to injure the femoral or humeral head (Fig. 3). Then, the dissection of the vessels proceeded.

\section{Fig. 1. The thickness of tunica adventitia and media layer}

We measured adventitia (outer) and media (inner) layer thicknesses using the NIS Elements AR software under a light microscope at $400 \times$ magnification (H\&E). (A) Cranial tibial artery, (B) basilic vein.
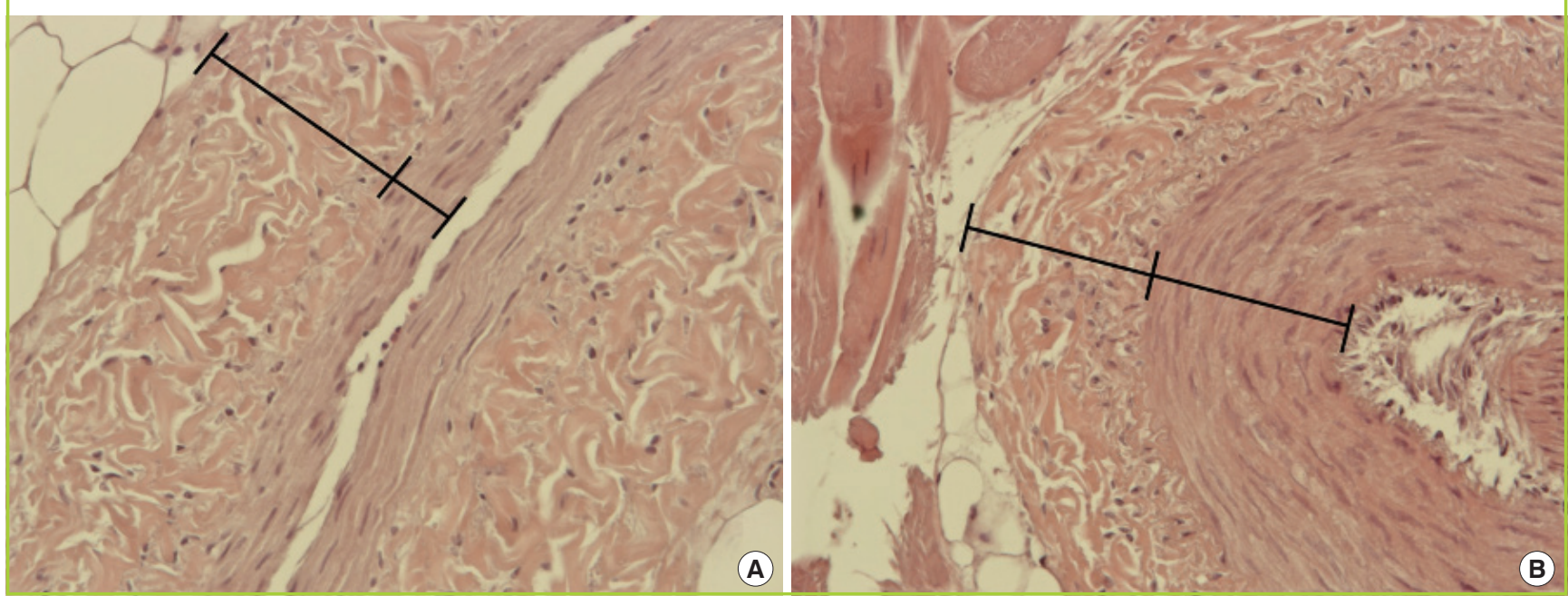

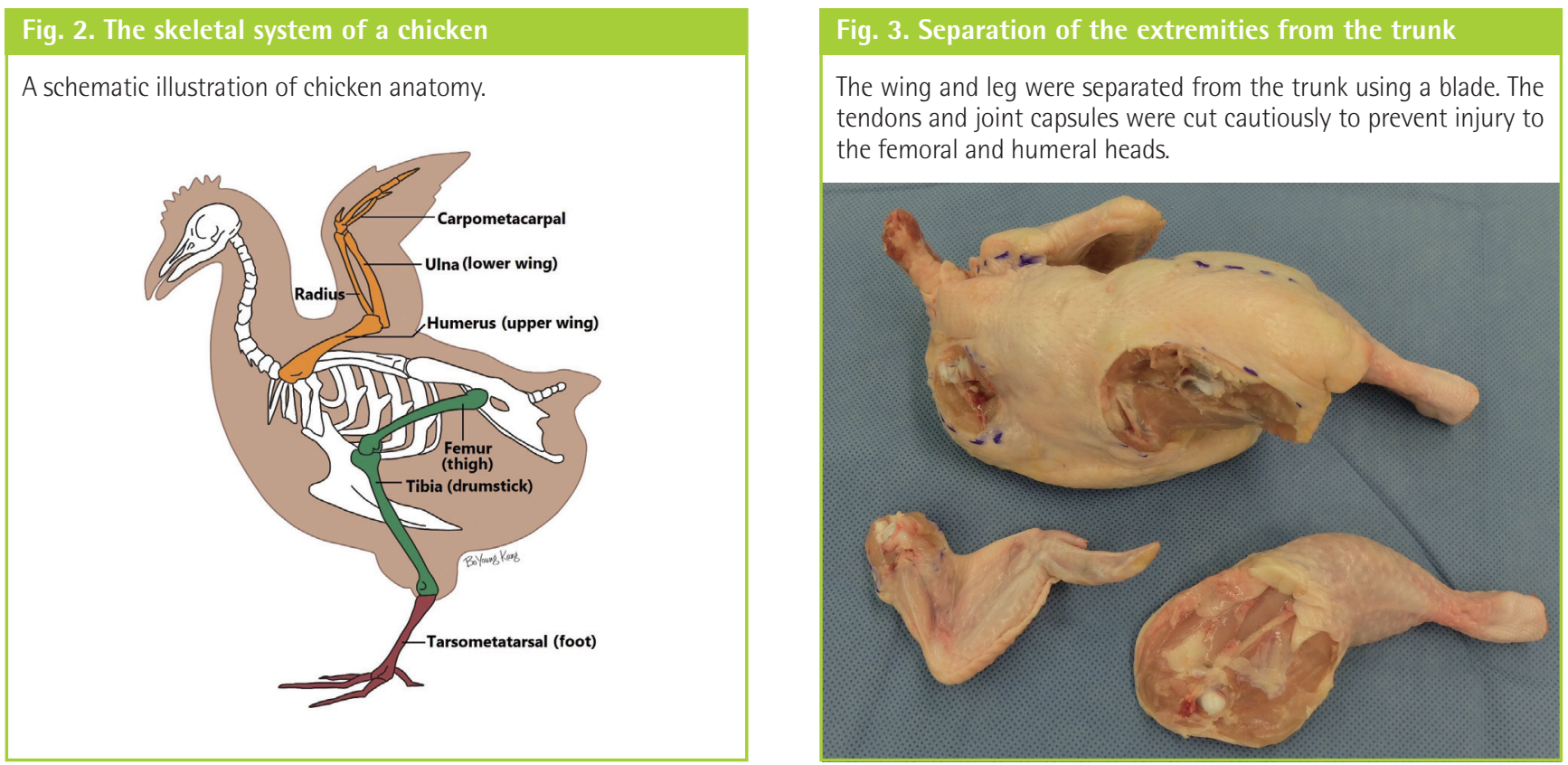

\section{Fig. 4. Vessels of the upper extremity}

(A) The basilic vein (white arrow) shows through the skin on the ventral side of the upper wing. The ulnar artery (black arrow) also shows through the skin of the lower wing. (B) The basilic vein (white arrow) lies on the skin flap and the brachial artery lies on the fascia of the biceps brachii muscle. A microvascular clamp was applied on the brachial artery. (C) The ulnar artery (white arrow) and radial artery (black arrow). (D) A microvascular clamp was applied on the ulnar artery.
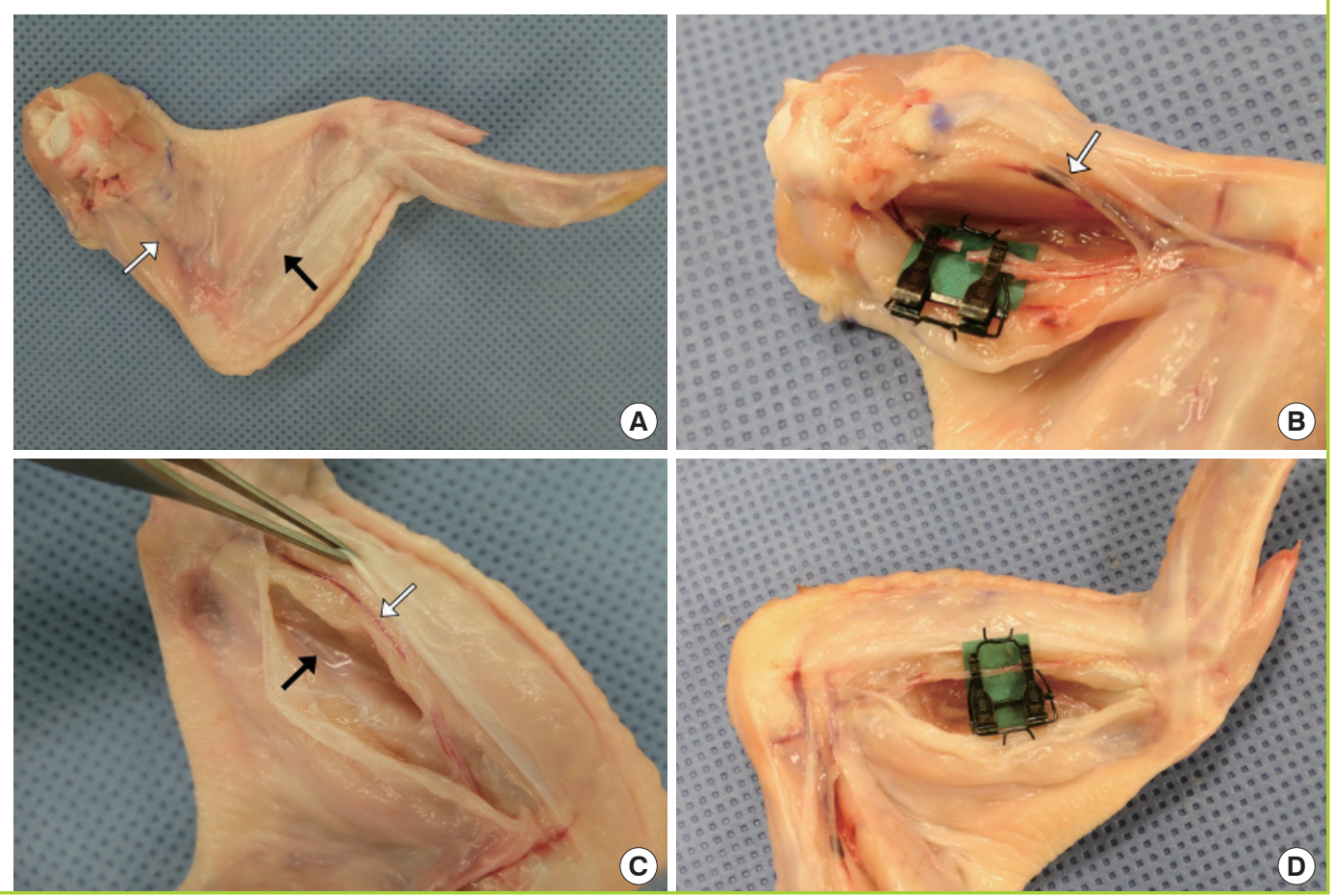

\section{Wings}

The basilic vein was evident through the skin on the ventral side of the upper wing (Fig. 4A). A skin incision was made on the groove formed by the biceps brachii and triceps brachii using Metzenbaum scissors. The brachial artery was found on the fascia of the biceps brachii muscle. All brachial arteries bifurcate at the level of the humeral shaft and divide into the ulnar and radial arteries (Fig. 4B). The ulnar artery was detected through the skin of the lower wing and above the fascia of the flexor digitorum superficialis. The dissection through the flexor digitorum superficialis and profundus muscles was deepened to reach the radial artery, which lies between them (Fig. 4C, D).

\section{Legs}

The ischiatic artery and vein were beneath the adductor profundus and superficialis muscles on the ventral side. The designa- 


\section{Fig. 5. Vessels of the lower extremity}

(A) A microvascular clamp was applied on the ischiatic artery. (B) The cranial tibial artery lies between the tibialis anterior (white arrow) and flexor perforans after elevating the peroneus longus muscle (black arrow). A microvascular clamp was applied on the cranial tibial artery. (C) The common dorsal metatarsal artery (white arrow) lies beneath the extensor tendon on the dorsal side. (D) A microvascular clamp was applied on the common dorsal metatarsal artery.
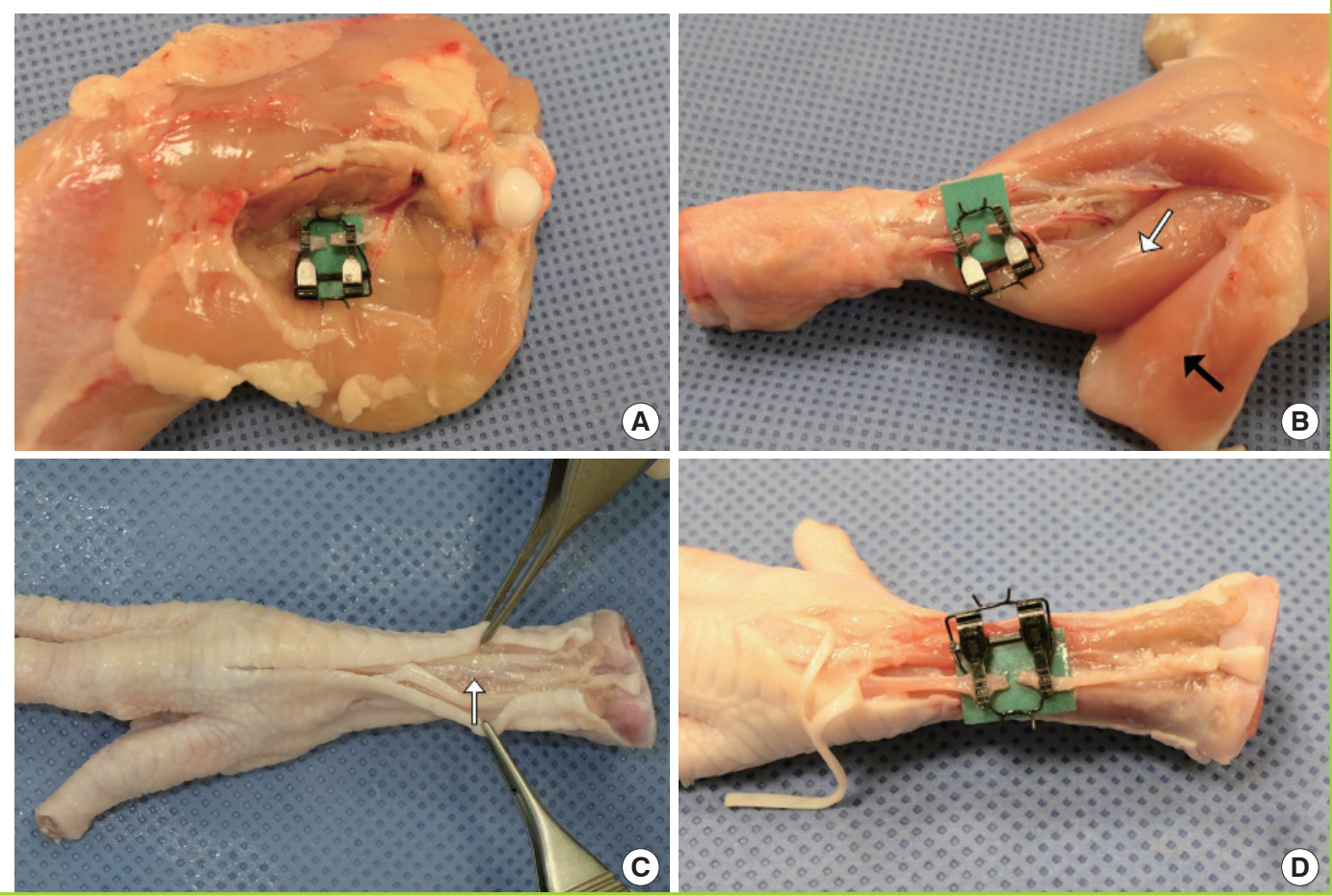

tion of the 'femoral vessel' of the chicken, commonly mentioned in other literature, is a misleading name; it is, in fact, the ischiatic vessel according to anatomical arterial studies of chickens by Swielim et al. [9] The adductor profundus and superficialis muscles were resected after transecting the femorocruralis muscle to expose the upper two-thirds of the ischiatic vessel (Fig. 5A). The cranial tibial artery descended between the tibialis anterior and flexor perforans et perforatus digiti II in the lower leg and appeared after resecting the peroneus longus muscle (Fig. $5 B$ ). The cranial tibial artery is the largest terminal branch of the popliteal artery. It continued from the popliteal artery by passing through the interosseous space at the upper one-third of the tibia and continued as the common dorsal metatarsal artery.

\section{Foot}

The common dorsal metatarsal artery lies beneath the extensor tendon on the dorsal side (Fig. 5C). The common dorsal metatarsal artery was detected after a midline skin incision on the dorsal side and elevation of the extensor tendon (Fig. 5D).

\section{Statistical analysis}

The sample size calculation for $80 \%$ power was performed by simple logistic regression with a continuous predictor in nQuery Adcisor 7.0. The association between ED and weight was assessed using linear regression analysis. The ED order in a single specimen was assessed by analysis of variance and the Tukey
Table 1. External diameter measurements of chicken arteries and veins

\begin{tabular}{|lcccc|}
\hline Vessel & No. & $\begin{array}{c}\text { Mean } \pm \text { SD } \\
(\mathbf{m m})\end{array}$ & $\begin{array}{c}\text { Minimum } \\
(\mathbf{m m})\end{array}$ & $\begin{array}{c}\text { Maximum } \\
(\mathbf{m m})\end{array}$ \\
\hline Ischiatic vein & 52 & $2.69 \pm 0.33$ & 2.00 & 3.40 \\
Basilic vein & 52 & $1.88 \pm 0.36$ & 1.15 & 2.70 \\
Ischiatic artery & 52 & $1.68 \pm 0.24$ & 1.15 & 2.20 \\
Common dorsal metatarsal artery & 30 & $1.23 \pm 0.23$ & 0.90 & 1.80 \\
Cranial tibial artery & 52 & $1.18 \pm 0.19$ & 0.90 & 1.90 \\
Brachial artery & 52 & $1.08 \pm 0.15$ & 0.90 & 1.55 \\
Ulnar artery & 52 & $0.82 \pm 0.13$ & 0.55 & 1.20 \\
Radial artery & 52 & $0.56 \pm 0.12$ & 0.35 & 0.90 \\
\hline No., sample number; SD, standard deviation. & & \\
\hline
\end{tabular}

post-hoc test. Statistical calculations were performed using the SPSS ver. 19.0 software (IBM Corp, Armonk, NY, USA). A Pvalue $<0.05$ was considered to indicate significance.

\section{RESULTS}

A total of 364 vessels were assessed in the 26 fresh chickens and 30 frozen feet. The mean fresh chicken weight was $1,066.89 \pm$ $245.20 \mathrm{~g}$ (range, 650-1,420 g).

The ischiatic vein had the largest ED of $2.69 \pm 0.33 \mathrm{~mm}$, followed by the basilic vein $(1.88 \pm 0.36 \mathrm{~mm})$, ischiatic artery $(1.68 \pm 0.24 \mathrm{~mm})$, common dorsal metatarsal artery $(1.23 \pm$ $0.23 \mathrm{~mm})$, cranial tibial artery $(1.18 \pm 0.19 \mathrm{~mm})$, brachial artery 
$(1.08 \pm 0.15 \mathrm{~mm})$, ulnar artery $(0.82 \pm 0.13 \mathrm{~mm})$, and radial artery $(0.56 \pm 0.12 \mathrm{~mm})$ (Table 1$)$. A significant positive correlation was detected between $\mathrm{ED}$ and specimen weight for all vessels $(\mathrm{P}<0.05)$, except the radial and cranial tibial arteries. The order of vessel size in a single specimen was consistent across all subjects (Fig. 6).

Vessel thicknesses of 121 vessels from 9 fresh chickens, and 12 vessels from 12 frozen chicken feet were measured. The ischiatic artery had the largest adventitia thickness of $158.66 \pm 40.25 \mu \mathrm{m}$, followed by the ischiatic vein $(131.09 \pm 29.20 \mu \mathrm{m})$, brachial artery $(120.93 \pm 22.10 \mu \mathrm{m})$, cranial tibial artery $(113.09 \pm 29.61$ $\mu \mathrm{m})$, basilic vein $(104.46 \pm 35.94 \mu \mathrm{m})$, common dorsal metatarsal artery $(86.50 \pm 20.01 \mu \mathrm{m})$, ulnar artery $(80.29 \pm 13.72 \mu \mathrm{m})$, and radial artery $(74.09 \pm 19.91 \mu \mathrm{m})$. The cranial tibial artery had the largest media thickness of $154.15 \pm 46.48 \mu \mathrm{m}$, followed by the ischiatic artery $(132.94 \pm 30.56 \mu \mathrm{m})$, brachial artery

\section{Fig. 6. Consistent order of external diameter}

The external diameter order was consistent within a single specimen. The interior of the box indicates the interquartile range of the data $(25 \%$ to $75 \%)$. The band inside the box is the sample mean and the diamond inside the box is the median. Lines extending vertically from the boxes indicate upper and lower quartiles and dots indicate extreme values.

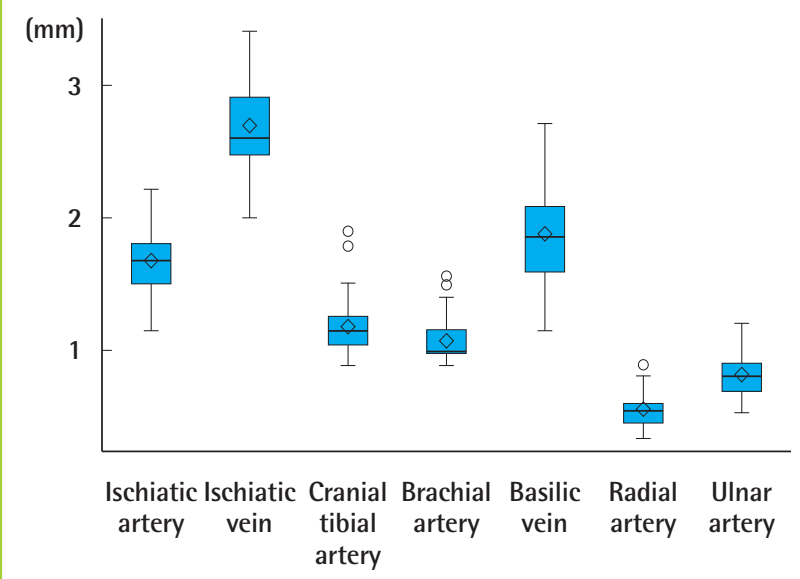

$(117.52 \pm 19.60 \mu \mathrm{m})$, common dorsal metatarsal artery $(114.14 \pm 16.61 \mu \mathrm{m})$, ulnar artery $(93.55 \pm 24.43 \mu \mathrm{m})$, radial artery $(90.33 \pm 30.72 \mu \mathrm{m})$, ischiatic vein $(41.64 \pm 15.38 \mu \mathrm{m})$, and the basilic vein $(31.2 \pm 7.13 \mu \mathrm{m})$. All veins had a thinner tunica media layer than that of arteries. The ratio of adventitia to media thickness ranged from 0.75 to 1.24 in arteries and 3.4 in veins (Table 2).

Mean dissection time was 118 seconds for the brachial artery, 97 seconds for the basilic vein, 81 seconds for the ulnar artery, and 87 seconds for the radial artery. In the lower extremities, a mean of 112 seconds was needed to dissect the ischiatic artery, 110 seconds for the ischiatic vein, and 122 seconds for the cranial tibial artery.

\section{DISCUSSION}

In the present study, we selected 8 chicken vessels and compared their characteristics. The vessels had different EDs and

Table 3. External diameter of human vessels

\begin{tabular}{|llc|}
\hline $\begin{array}{l}\text { Range } \\
(\mathbf{m m})\end{array}$ & \multicolumn{1}{c}{ Vessels } & $\begin{array}{c}\text { External diameter } \\
(\mathbf{m m})\end{array}$ \\
\hline$>3 \mathrm{~mm}$ & Deep inferior epigastric artery [10] & 3.2 \\
& Deep inferior epigastric vein [10] & 3.1 \\
$2-3 \mathrm{~mm}$ & Radial artery [11] & 2.54 \\
& Ulnar artery [11] & 2.12 \\
& Internal mammary artery [12] & $2.36 \pm 0.5$ \\
& Posterior tibial artery [13] & $2.34 \pm 0.5$ \\
& Superficial temporal vein [14] & 2 \\
$1-2 \mathrm{~mm}$ & Thoracodorsal artery [12] & $1.79 \pm 0.34$ \\
& Facial artery [14] & 1.48 \\
& Superficial temporal artery [14] & 1.4 \\
& Common digital artery [15] & $1.7 \pm 0.2$ \\
& 2nd Internal mammary perforating artery [16] & $1 \pm 0.4$ \\
$0-1 \mathrm{~mm}$ & Facial perforating artery [17] & 0.96 \\
& Thoracodorsal perforating artery [18] & 0.9 \\
& Digital artery [19] & $0.4-0.7$ \\
& Digital terminal artery [20] & $0.3-0.7$ \\
\hline
\end{tabular}

Table 2. Vessel wall thicknesses of chicken arteries and veins

\begin{tabular}{|lcccc|}
\hline Vessel & No. & $\begin{array}{c}\text { Tunica adventitia } \\
\text { Mean } \pm \text { SD }(\mu \mathrm{m})\end{array}$ & $\begin{array}{c}\text { Tunica media } \\
\text { Mean } \pm \text { SD }(\mu \mathrm{m})\end{array}$ & Adventitia/Media ratio \\
\hline Cranial tibial artery & 18 & $113.09 \pm 29.61$ & $154.15 \pm 46.48$ & $0.83 \pm 0.41$ \\
Ischiatic artery & 18 & $158.66 \pm 40.25$ & $132.94 \pm 30.56$ & $1.24 \pm 0.33$ \\
Brachial artery & 18 & $120.93 \pm 22.10$ & $117.52 \pm 19.60$ & $1.05 \pm 0.25$ \\
Metatarsal artery & 12 & $86.50 \pm 20.01$ & $114.14 \pm 16.61$ & $0.75 \pm 0.07$ \\
Ulnar artery & 18 & $80.29 \pm 13.72$ & $93.55 \pm 24.43$ & $0.92 \pm 0.27$ \\
Radial artery & 18 & $74.09 \pm 19.91$ & $90.33 \pm 30.72$ & $0.90 \pm 0.39$ \\
Ischiatic vein & 16 & $131.09 \pm 29.20$ & $41.64 \pm 15.38$ & $3.41 \pm 1.05$ \\
Basilic vein & 16 & $104.46 \pm 35.94$ & $31.2 \pm 7.13$ & $3.38 \pm 1.26$ \\
\hline No., sample number; SD, standard deviation. & & & \\
\hline
\end{tabular}


vessel wall thicknesses, all of which were prepared without difficulty. This information will facilitate selection of the most suitable model for microanastomosis training. Furthermore, these results show that the chicken is a valuable microvascular anastomosis training model, as trainees can practice on various vessels according to their proficiency with a short dissection time.

The chickens provided various sizes of vessels, which were comparable to human vessels (Table 3) [10-20]. The ED of the ischiatic vein was 2-3 mm and that of the basilic vein was 1-3 $\mathrm{mm}$. The EDs of the ischiatic, cranial tibial, brachial, and common dorsal metatarsal arteries were 1-2 mm, whereas the EDs of the ulnar and radial arteries were $<1 \mathrm{~mm}$ in most specimens. Vessel ED is closely associated with the difficulty of a microvascular procedure, which can influence the choice of microvascular training model. Large caliber vessels are relatively straightforward and are better for novices as a practice model. Conversely, small-sized vessels require more careful and delicate maneuvers, which might be more suitable for more experienced trainees. The ED of the radial artery was almost $<0.8 \mathrm{~mm}$, which is a suitable size for supermicrosurgical training. Chen el al. [21] demonstrated that supermicrosurgical anastomoses can be performed using branches of the ischiatic vessels of chickens. 21 Chickens provide vessels with a broad range of EDs, enabling trainees to choose the most appropriate training model for them.

Vessel wall thickness can also affect the difficulty level of a microsurgical procedure. Vessels with thinner walls are prone to easy injury and collapse during the anastomosis. Because the adventitia is peeled off before anastomosis and the intima layer is too thin, needle resistance as it passes through the vessel wall might depend on the thickness of the media layer. Veins always have a thinner tunica media than arteries, as in humans. Among the 6 arteries evaluated, the cranial tibial artery had the largest average thickness of the media layer. Thus the cranial tibial artery tends to maintain a cylindrical shape even after being cut, which is suitable for novice trainees. However, when comparing the thickness of the tunica media of chicken vessels to the internal mammary $(291.3 \mu \mathrm{m})$ and deep inferior epigastric arteries $(193.5 \mu \mathrm{m})$ of human vessels, chickens have thinner media layers than those of humans [22].

Preparation time from the beginning of the skin incision to securing the vessel with a double apposing clamp was $<3 \mathrm{~min}$ for all vessels. Because time was measured by an experienced surgeon, a novice might take longer. However, trainees who follow the recommended approach described in this study will take less time, regardless of the model.

Chicken anatomy is consistent in features such as vessel position, bifurcation, and vessel passing pattern with the bony groove pattern. The basilic and ischiatic veins are exposed during muscle dissection to identify the brachial and ischiatic arteries. Arteries attached to a parallel nerve, such as the brachial, cranial tibial, and common dorsal metatarsal arteries, take more time to isolate from the nerve. Isolating arteries covered by thick fibrous fascia, such as the brachial and radial arteries, is also difficult. The brachial artery may sometimes bifurcate so close to the humeral head that the ulnar or radial arteries in the upper wing are more suitable for practice in the upper extremity part. The tendency toward a cylindrical shape was strong for the ischiatic and cranial tibial arteries, which was correlated with media thickness.

Based on these results, we recommend that novice trainees start with the ischiatic artery, which has a relatively thick ED and low levels of dissection and isolation difficulty. Then, the cranial tibial, brachial, or common dorsal metatarsal arteries are suitable models for training. Lastly, smaller vessel microanastomosis or super microanastomosis practice is possible with the ulnar and radial arteries.

The limitations of chicken vessels as microanastomosis training models include the lack of hemodynamic circulation and thrombosis. Although circulation cannot be reproduced without a special pump system [23], the quality of the anastomosis can be checked by splitting the vessels longitudinally and examining the sutures. Patency and leakage tests can be conducted by injecting dye with a cannula [5]. The limitation of this study is that the range in the weight of the chicken samples was somewhat broad $(650-1,420 \mathrm{~g})$. If we had analyzed chickens within a specific range of weight, the results would have been more reliable for this narrower range.

Chickens cost only \$4 USD (1 kg), which is inexpensive, considering that a $200-300 \mathrm{~g}$ rat costs about $\$ 10$ USD and silicone tubing $>\$ 70$ USD. Trainees can practice self-customized training, because they are not limited by time and place. Furthermore, chickens remain fresh for 5 days. Finally, $<5$ minutes is needed from beginning the dissection to securing the vessel with microvascular clamps when the trainee becomes proficient. This comprehensive comparison can help trainees choose suitable vessels for microvascular anastomosis practice depending on their purpose and skill.

\section{REFERENCES}

1. Couceiro J, Ozyurekoglu T, Sanders S, et al. Microsurgical training regimen with nonliving chicken models. Microsurgery 2013;33:251-2.

2. Abla AA, Uschold T, Preul MC, et al. Comparative use of turkey and chicken wing brachial artery models for microvas- 
cular anastomosis training. J Neurosurg 2011;115:1231-5.

3. Lannon DA, Atkins JA, Butler PE. Non-vital, prosthetic, and virtual reality models of microsurgical training. Microsurgery 2001;21:389-93.

4. Kim BJ, Kim ST, Jeong YG, et al. An efficient microvascular anastomosis training model based on chicken wings and simple instruments. J Cerebrovasc Endovasc Neurosurg 2013;15:20-5.

5. Govila A. A simple model on which to practise microsurgical technique: a fresh chicken. Br J Plast Surg 1981;34:486-7.

6. Hino A. Training in microvascular surgery using a chicken wing artery. Neurosurgery 2003;52:1495-7.

7. Galeano M, Zarabini AG. The usefulness of a fresh chicken leg as an experimental model during the intermediate stages of microsurgical training. Ann Plast Surg 2001;47:96-7.

8. Satterwhite T, Son J, Echo A, et al. The chicken foot dorsal vessel as a high-fidelity microsurgery practice model. Plast Reconstr Surg 2013;131:311e-312e.

9. Elgammal SM, Swielim GA, Khalifa EF, et al. Anatomical studies on the arterial blood supply of the pelvic limb of chicken. Suez Canal Vet Med J 2012;2:171-19.

10. Colohan S, Maia M, Langevin CJ, et al. The short- and ultrashort-pedicle deep inferior epigastric artery perforator flap in breast reconstruction. Plast Reconstr Surg 2012;129:331-40.

11. Kiray A, Ergur I, Tayefi H, et al. Anatomical evaluation of the superficial veins of the upper extremity as graft donor source in microvascular reconstructions: a cadaveric study. Acta Orthop Traumatol Turc 2013;47:405-10.

12. Feng LJ. Recipient vessels in free-flap breast reconstruction: a study of the internal mammary and thoracodorsal vessels. Plast Reconstr Surg 1997;99:405-16.

13. Xu Z, Chenglin L, Zhiwen N, et al. Use of flap based on posterior tibial artery for free transfer. J Reconstr Microsurg 2007;23:361-5.

14. Doscher M, Charafeddine AH, Schiff BA, et al. Superficial temporal artery and vein as recipient vessels for scalp and fa- cial reconstruction: radiographic support for underused vessels. J Reconstr Microsurg 2015;31:249-53.

15. Hazani R, Elston J, Brooks D, et al. Bridging the gap in hand replantation: use of the common digital artery for completion of the superficial palmar arch. Plast Reconstr Surg 2010;126:2037-42.

16. Gillis JA, Prasad V, Morris SF. Three-dimensional analysis of the internal mammary artery perforator flap. Plast Reconstr Surg 2011;128:419e-426e.

17. Qassemyar Q Havet E, Sinna R. Vascular basis of the facial artery perforator flap: analysis of 101 perforator territories. Plast Reconstr Surg 2012;129:421-9.

18. Thomas BP, Geddes CR, Tang M, et al. The vascular basis of the thoracodorsal artery perforator flap. Plast Reconstr Surg 2005; 116:818-22.

19. Ozcelik IB, Purisa H, Sezer I, et al. The results of digital replantations at the level of the distal interphalangeal joint and the distal phalanx. Acta Orthop Traumatol Turc 2006;40: 62-6.

20. Venkatramani H, Sabapathy SR. Fingertip replantation: Technical considerations and outcome analysis of 24 consecutive fingertip replantations. Indian J Plast Surg 2011;44: 237-45.

21. Chen WF, Eid A, Yamamoto T, et al. A novel supermicrosurgery training model: the chicken thigh. J Plast Reconstr Aesthet Surg 2014;67:973-8.

22. Jeong WS, Yun J, Lee TJ, et al. Histologic comparison between the internal mammary artery and the deep inferior epigastric artery and clinical implications for microsurgical breast reconstruction. J Plast Surg Hand Surg 2015;49:2347.

23. Phoon AF, Gumley GJ, Rtshiladze MA. Microsurgical training using a pulsatile membrane pump and chicken thigh: a new, realistic, practical, nonliving educational model. Plast Reconstr Surg 2010;126:278e-279e. 